\title{
Limited mid palmar versus extended incision in surgical treatment of carpal tunnel syndrome: Clinical analysis
}

\begin{tabular}{|c|c|c|c|}
\hline J agar Omar Doski' ${ }^{1 *}$ & Reber Saeed Sindy ${ }^{2}$ & Farhad Taher Hamzani² & Hishyar Osman Omar² \\
\hline
\end{tabular}

Background and objective: There are different methods and incisions to release the transverse carpal ligament in carpal tunnel syndrome. This study aimed to compare the surgical outcome of the conventional extended incision with the limited mid palmar one.

Methods: The study was a prospective comparative one. Patients with carpal tunnel syndrome were divided into two groups: Group 1 was patients operated on by the conventional extended incision, Group 2 with a limited mid palmar incision.

Results: The patients included were 79 with 89 hands. The age mean was 41 years. Group 1 included 47, and Group 2 included 42 hands. The differences between both groups were statistically significant regarding the operative data (the incision length and the operative time) and the post-operative data (the duration of analgesia needed, the date of starting to use the hand in daily life activities, and return to work). However, the date of improvement of the sensory symptoms from the fingers showed no significant differences. The sum of the overall complications that occurred for the cases of Group 2 was about a third of that occurred for Group 1. The highly significant difference was in the scar tenderness in the third month of the post-operative period.

Conclusion: The limited mid palmar incision to release the entrapment of median nerve in carpal tunnel syndrome offers a shorter operative time, less analgesia needed post-operatively, less complication rate, less scar tenderness, earlier use of the hand in daily life activities, and return to work in a shorter period.

Keywords: Carpal tunnel syndrome; Surgical treatment; Incision.

\section{Introduction}

Carpal tunnel syndrome (CTS) is the most common peripheral entrapment neuropathy. The treatment strategy is a spectrum between conservative treatment and surgery. For patients in whom conservative treatment fails, surgical decompression is indicated. ${ }^{1,2}$ Conventional open release with a single extended incision has been the standard approach worldwide since Phalen promoted it in the 1950s. It is a relatively safe operation, but it has some complications like hypertrophic scarring, scar tenderness, pillar pain, and delayed return to work. ${ }^{3-7}$ Therefore, this operation with conventional incision had been extensively reviewed, and many modifications had been suggested with different instruments and incision techniques, such as a limited mid palmar incision, single transverse wrist incision, two small incisions, and endoscopy. ${ }^{5-12}$ The latter was considered superior to open release regarding post-operative morbidity with faster return to normal activities, including the return to work. However, it is still considered to have a high complication rate, need special instruments and experience. , $6,8,13-15$ The limited open mid palmar incision is considered easier to perform than the endoscopic method and does not require special equipment. This study aimed to compare the surgical outcome of the conventional extended incision with the limited mid palmar one.

${ }^{1}$ Department of Surgery, College of Medicine, University of Duhok, Duhok, I raq.

2 Emergency Teaching Hospital, Duhok, I raq.

* Correspondence: jagaromar@uod.ac 


\section{Methods}

The agreements to conduct this study were gained from the Committee of Ethics at the General Directorate of the Health at the Duhok Governorate (reference number 27032018-1). The study was a prospective comparative one. The patients selected for this study were those who had clinical evidence of CTS and documented by nerve conduction study. Those patients who did not improve by conservative measures for more than three months were included in this study. Those patients who had a previous history of fractures around the wrist or had a recurrence of the symptoms after a previous CTS surgery were excluded from this study. The patients were operated on by different orthopedics and neurosurgeons at Duhok Emergency Teaching Hospital between the $1^{\text {st }}$ of March

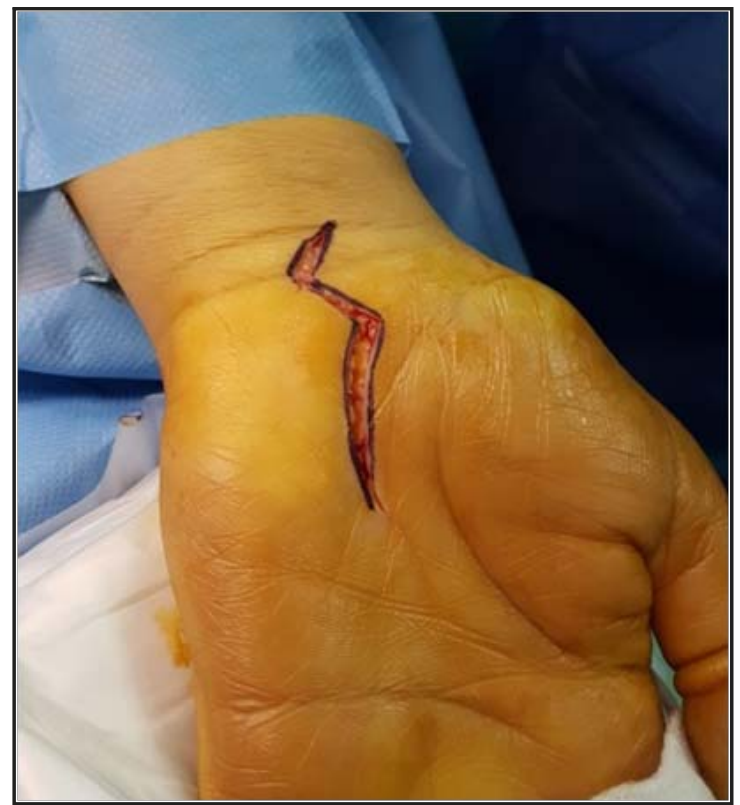

Figure 1: Example of the conventional extended long incision for CTS surgery.
2017 and $30^{\text {th }}$ of November 2018. Each patient was followed up for a minimum of three months after the operation. The patients were divided into two groups. Group 1 were patients operated by the conventional extended incision. The procedure involved a curvilinear incision going from the palm onto the distal forearm with a length of more than $4 \mathrm{~cm}$. The incision was curved, ulnar, and parallel to the mid palmar crease. It continued proximally onto the wrist and distal forearm with angles in a zigzag manner to avoid crossing the flexor wrist creases at right angles). These patients were considered as a control group (Figure 1). Group 2 were those for whom the limited mid palmar short incision (Figure 2) was done.

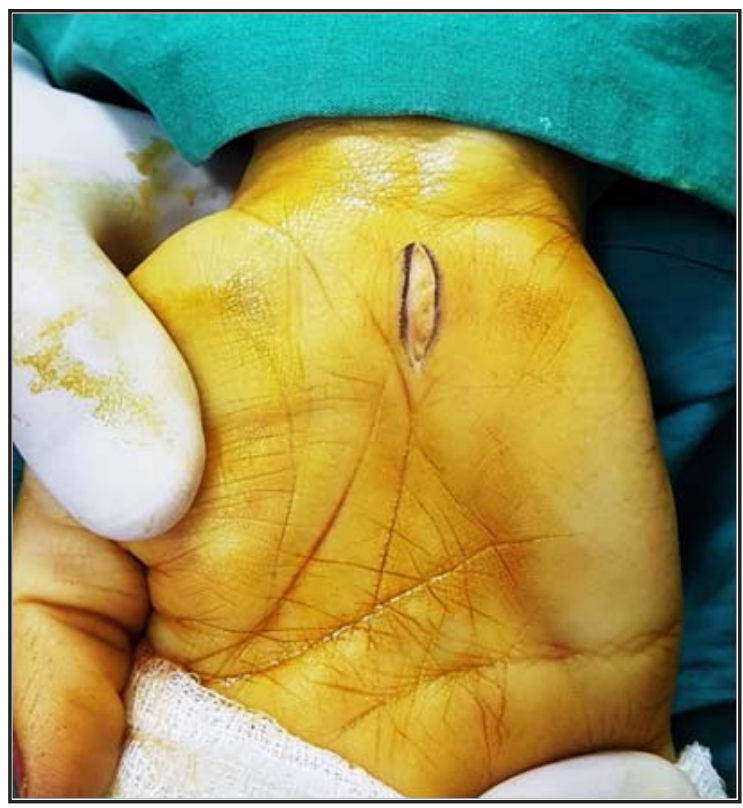

Figure 2: Example of the limited mid palmar short incision for CTS surgery. 
The procedure involved a short longitudinal incision at the middle aspect of the proximal palm just ulnar to the mid palmar crease with a length less than $4 \mathrm{~cm}$. The transverse carpal ligament was opened gently from its center. Then by using hooked retractors for the elevation of the skin and subcutaneous tissue layers, the remaining parts of the carpal ligament were released proximally and distally under direct vision. Each surgeon was free to choose the type of incision to conduct the surgery for his patient. The patients were randomly distributed between both groups. The data of each patient were recorded in a special file. Each file included four parts.

Part 1 (pre-operative data) included name, age, gender, occupation, duration of symptoms, and grade of median nerve entrapment according to the nerve conduction study report.

Part 2 (operative data) included the type of incision, length of incision, and duration of operative time.

Part 3 (post-operative data) included duration of pain that need analgesia (in days), date of improvement of the sensory changes in the fingers (in weeks), and date of starting using the hand in daily activities and return to work (in weeks).

Part 4 (complications occurred) included bleeding, infection, new sensory changes in thenar eminence, pillar pain, persistent symptoms of CTS, scar tenderness, and scar hypertrophy at the end of the $3^{\text {rd }}$ month.

The results were analyzed statistically using the statistical package for the social sciences software program version 17 . The comparison between both groups was made by using the independent sample Student's t-test (2-sided) for comparing the means of numerical variables (scale variables) of both groups (Group 1 and Group 2). In the case of categorical variables, the comparison between the groups was made by using the Pearson Chi-Square test. However, when the expected value of more than $20 \%$ of the cells of the table was less than 5 , then the $P$-value was obtained by Fisher's Exact test. The result was considered statistically significant when the $P$-value was equal or less than 0.05 and highly significant when it was equal or less than 0.001 .

\section{Results}

The patients with CTS included in this study were 79 . Eleven $(13.9 \%)$ patients were males, and $68(86.1 \%)$ were females with a male: female ratio of $0.16: 1$. The mean of their age was $41.08 \pm 9.284$ (range 24-65) years. Their occupation varies from housewives to specialist doctors. Ten of them had bilateral CTS, so the total cases operated on were 89 hands. The mean duration of their symptoms before the operation was 12 months (range from 5 months to 4 years). According to the nerve conduction study results, most of the patients had a severe degree of entrapment of their median nerves in the carpal tunnel space, apart from 6 cases that had extreme compression. Five of the cases were pregnant ladies, two in the $2^{\text {nd }}$ trimester and three in the $3^{\text {rd }}$ trimester period. Group 1 of patients included 47 (52.8\%) hands, while Group 2 included $42(47.2 \%)$ hands. Those patients with bilateral CTS were 10 (20 hands). The conventional extended incision operation was done for three of them ( 6 hands) and by the short, mid palmar incision for two patients (4 hands). For the other five patients (i.e., 10 hands), both types of incisions were done for them, each type for each hand. The differences between both groups regarding operative data (incision length and operative time) were summarized in Table 1. The mean incision length of Group 2 was about a third of that of Group 1 (2.581 versus 6.013 centimeters), and the operative time for Group 2 was about half of that for Group 1 (11.35 versus 22.58 minutes). These two differences were statistically significant $(P<0.001)$. In the post-operative data, the difference between both groups regarding the duration of pain in the post-operative 
period that need analgesia and date of return to work, both had statistically significant values $(P=0.020$ and 0.001$)$. However, the date of sensory symptoms improvement did not show any significant difference between both groups $(P=0.657)$, as shown in Table 2 . The sum of overall complications in Group 1 was about three folds of that of Group 2. The differences between the frequency of the complications in both groups had no statistically significant value apart from that for scar tenderness $(P=0.001)$, as shown in Table 3.

Table 1: The differences between both groups regarding the operative data.

\begin{tabular}{lcccc}
\hline & $\begin{array}{c}\text { Group 1 } \\
\text { M (SD) }\end{array}$ & $\begin{array}{c}\text { Group 2 } \\
\text { M (SD) }\end{array}$ & MD & P value \\
\hline Incision length (cm) & $6.013(0.577)$ & $2.581(0.254)$ & 3.4325 & $<0.001$ \\
Operative time (min) & $22.58(3.156)$ & $11.35(2.501)$ & 11.224 & $<0.001$ \\
\hline
\end{tabular}

M: mean; SD: standard deviation; MD: mean difference; cm: centimeter; min: minute

Table 2: The differences between both groups regarding the post-operative data.

\begin{tabular}{lcccc}
\hline & $\begin{array}{c}\text { Group 1 } \\
\text { M(SD) }\end{array}$ & $\begin{array}{c}\text { Group 2 } \\
\text { M(SD) }\end{array}$ & MD & P value \\
\hline Duration of pain that need analgesia (d) & $9.74(5.075)$ & $7.43(4.013)$ & 2.316 & 0.020 \\
Date of sensory symptoms improvement (w) & $4.28(1.015)$ & $4.19(0.773)$ & 0.086 & 0.657 \\
Date of return to work (w) & $6.11(1.536)$ & $4.90(1.605)$ & 1.202 & 0.001 \\
\hline
\end{tabular}

M: mean; SD: standard deviation; MD: mean difference; d: days; w: weeks

Table 3: The number and percentage of each type of operative complication in both groups.

\begin{tabular}{lccc}
\hline Type of complication & Group 1 (n=47) & Group 2 (n=42) & $\boldsymbol{P}$ value \\
\hline Bleeding & $0(0 \%)$ & $0(0 \%)$ & - \\
Infection & $2(4.3 \%)$ & $0(0 \%)$ & $0.496^{*}$ \\
New sensory changes in thenar eminence & $0(0 \%)$ & $0(0 \%)$ & - \\
Pillar pain & $6(12.8 \%)$ & $5(11.9 \%)$ & 0.902 \\
Persistent symptoms of CTS & $0(0 \%)$ & $2(4.8 \%)$ & $0.220^{*}$ \\
Scar tenderness & $16(34.0 \%)$ & $2(4.8 \%)$ & $0.001^{*}$ \\
Scar hypertrophy & $0(0 \%)$ & $0(0 \%)$ & - \\
Sum of overall complications & 24 & 9 & \\
\hline${ }^{*}: P$-value by Fisher's Exact test & & & \\
\hline
\end{tabular}




\section{Discussion}

Post-operative assessment of the patient after surgery for carpal tunnel syndrome may include a variety of methods. Some of these methods include digital sensory measurements, motor tests like grip and pinch strength measurements, and patient-rated symptom severity and functional status scales (like Boston Carpal Tunnel Questionnaire, the Michigan Hand Outcome Questionnaire, the quick form of the Disabilities of the Arm, Shoulder and Hand Questionnaire, and the Duruoz Hand Index). ${ }^{16,17}$ Others concentrate on the scar tenderness and the time of starting to use the hand in daily activities and return to work. The long-term follow-up of the cases that underwent release of the carpal ligament by using sensory and motor tests appeared to be comparable and nearly the same. The main complaint of the patients was about the scar of the surgery and the date of starting to use their hand in daily activities and return to work. ${ }^{5,6,9,11,14,15,18-20}$ Therefore, the later points were of interest for clinical analysis of the results of this study. The differences between both groups were statistically significant regarding the operative data. This is an important point for any operative procedure to decrease the surgical exposure of tissues and decrease the anesthesia required. Jugovac et al. (2002) also found a significant difference between the groups of their study regarding the operative time and the scar length. ${ }^{21}$ The difference between the results of their study and the present one was in the mean difference (1.6 versus 11.2 minutes for the operative time and 2.7 versus $3.4 \mathrm{~cm}$ for the scar length). The differences between both groups were also statistically significant regarding the post-operative data. The duration of analgesia needed in the post-operative period by the patients of Group 2 (those with a short incision) was less than those of Group 1 (those with a long incision). This may be due to a reduced amount of tissue destruction during surgical dissection and subsequent inflammatory processes that follow it. This point is clinically important to decrease the suffering and complain of the patients from the surgery. The quality (type) and the quantity (amount) of analgesia used may also be different, and to declare that another study may be required. During the literature review, no previously published article was found comparing the duration of analgesia needed in the post-operative period. The date of improvement of the sensory symptoms of CTS from the fingers had no significant differences $(P=0.657)$ between both groups. This may be expected because the internal procedure involving the transverse carpal ligament division to relieve the compression on the median nerve is the same regardless of the length of the skin incision. The results of other studies also did not find a significant difference regarding sensory symptoms relief in the fingers in the post-operative period between the different surgical methods for carpal tunnel decompression. ${ }^{8,21}$ It is interesting to notice the differences between the two groups regarding the date of starting to use the hand in daily activities and return to work. Most of the patients of Group 2 were able to use their hands in their daily life activities earlier, and they were encouraged to return to their work in a shorter period (less than 5weeks). This statistically highly significant difference $(P=0.001)$ between both groups is important clinically because it may decrease the impacts of the surgery on the patients' life during the post-operative period and may shorten the recovery period. This difference was noticed and described more clearly by those patients who had bilateral CTS, and the operation was done for their both hands by different methods (five patients with ten hands). Other studies also found that those patients with minimal incision start to use their hands in daily activities in a shorter period and return to work earlier with shorter sick leave. ${ }^{8,14,18,20-23}$ The sum of the overall complications that occurred for 
all cases of Group 2 was about a third of that occurred for the cases of Group 1 (9 versus 24). Two cases of Group 1 developed superficial wound infection, and they were known cases of diabetes mellitus. In reverse, two cases of group 2 did not show improvement of their CTS symptoms even after three months from the date of operation. This indicates the failure of CTS surgery, and it may be due to inadequate release of the transverse carpal ligament. This complication may occur because the incision done for them was short, and the field of surgery was relatively tight. However, the result was statistically not significant $(P=0.220)$. The difference was also statistically not significant $(P=0.902)$ between both groups regarding the occurrence of pillar pain. This may be because the internal procedure (that involves the release of the transverse carpal ligament) was the same regardless of the type and length of the skin incision. During the literature review, some articles $^{11,24}$ described lesser complication rates in patients with minimal incision, and others $^{8,10,20}$ showed no difference in the incidence of complications compared to those with the long incision. Interestingly, the difference between both groups regarding scar tenderness at the $3^{\text {rd }}$ month of the post-operative period was statistically highly significant $(P=0.001)$. Although none of the cases in either group developed scar hypertrophy, the patients of Group 2 were satisfied more with their scar and the esthetic outcome. This difference was described more clearly by those patients who had bilateral CTS, and the operation was done for their both hands by different methods (five patients with ten hands). Some investigators did not found any difference between both groups regarding the scar complaint, ${ }^{20,25}$ but others described a significant difference. ${ }^{10,21,23}$ Tarallo et al. used the Vancouver Scar Scale for scar evaluation, and we did not apply it for the patients included in this study because we suspect it is more suitable for burn scars. ${ }^{10}$
In general, the results of the present study were comparable with those of other researchers, and they are in favor of the short, limited mid palmar incision. ${ }^{10,21,23}$ We agree with Bromley (1994) that this minimal open technique provides a good alternative for the endoscopic way of decompression with an acceptable esthetic outcome and minimal morbidity. ${ }^{23}$ Interestingly, a survey for the members of the American Association for Hand Surgery in 2012 found the mini-open technique to be more preferred $(45.5 \%)$ than the longer incision $(33.3 \%)$ and the endoscopic one $(19.5 \%)$ for treatment of CTS. ${ }^{26}$

\section{Conclusion}

The limited mid palmar incision to release the entrapment of median nerve in carpal tunnel syndrome offers a shorter operative time, less need for postoperative analgesia, less complication rate, less scar tenderness, earlier use of the hand in daily life activities, and faster return to work.

\section{Competing interests}

The authors declare no competing interests.

\section{References}

1. Bickel K. Carpal tunnel syndrome. J Hand Surg Am 2010; 35(1):147-52.

2. Thatte MR, Mansukhani KA. Compressive neuropathy in the upper limb. Indian J Plast Surg 2011; 44(2):283-97.

3. Karl JW, Gancarczyk SM, Strauch RJ. Complications of carpal tunnel release. Orthop Clin North Am 2016; 47(2):425-33.

4. Faucher GK, Daruwalla JH, Seiler JG. Complications of surgical releaselbreak of carpal tunnel syndrome: A systematic review. J Surg Orthop Adv 2017; 26(1):18-24.

5. Sayegh ET, Strauch RJ. Open versus endoscopic carpal tunnel release: A metaanalysis of randomized controlled trials. Clin Orthop Relat Res 2015; 473(3):1120-32.

6. Mintalucci DJ, Leinberry CF. Open versus endoscopic carpal tunnel release. Orthop Clin North Am 2012; 43(4):431-7.

7. Khan AA, Ali H, Ali K, Muhammad G, Rashid B, Gul N, et al. Outcome of open carpal tunnel release surgery. J Ayub Med Coll Abbottabad 2015; 27(3):640-42.

8. Larsen MB, Sørensen Al, Crone KL, Weis T, Boeckstyns ME. Carpal tunnel release: 
a randomized comparison of three surgical methods. J Hand Surg Eur 2013; 38(6):646-50.

9. Bai J, Kong L, Zhao H, Yu K, Zhang B, Zhang J, et al. Carpal tunnel release with a new mini-incision approach versus a conventional approach, a retrospective cohort study. Int J Surg 2018; 52:105-9.

10. Tarallo M, Fino P, Sorvillo V, Parisi P, Scuderi N. Comparative analysis between minimal access versus traditional accesses in carpal tunnel syndrome: A perspective randomised study. J Plast Reconstr Aesthet Surg 2014; 67(2):237-43.

11. Yücetaş SC, Yildirim A. Comparative results of standard open and mini open, KnifeLight instrument-assisted carpal tunnel release. J Neurol Surg A Cent Eur Neurosurg 2013; 74(6):393-9.

12. Siegmeth AW, Hopkinson-Woolley JA. Standard open decompression in carpal tunnel syndrome compared with a modified open technique preserving the superficial skin nerves: A prospective randomized study. J Hand Surg Am 2006; 31(9):1483-9.

13. Nagle DJ. Endoscopic carpal tunnel release. Hand Clin 2002; 18(2):307-13.

14. Kohanzadeh S, Herrera FA, Dobke M. Outcomes of open and endoscopic carpal tunnel release: a meta-analysis. Hand (N Y) 2012; 7(3):247-51.

15. Michelotti B, Romanowsky D, Hauck RM. Prospective, randomized evaluation of endoscopic versus open carpal tunnel release in bilateral carpal tunnel syndrome: an interim analysis. Ann Plast Surg 2014; 73(2):S157-60.

16. Boston Carpal Tunnel Questionnaire. (Accessed November 20, 2020, at https://journals.plos.org/plosone/article/file? $\mathrm{i} d=\mathrm{i} n \mathrm{fo}: \mathrm{do}$ i / $10.1371 / \mathrm{j}$ o u rnal . pone.0129918.s002\&type=supplementary).

17. Yücel H, Seyithanoğlu H. Choosing the most efficacious scoring method for carpal tunnel syndrome. Acta Orthop Traumatol Turc 2015; 49(1):23-9.

18. Tzaan WC, Lui TN, Lee ST. Midpalmar accurate incision for carpal tunnel release. Chang Gung Med J 2005; 28(2):97-103.

19. Murthy PG, Goljan P, Mendez G, Jacoby SM, Shin EK, Osterman AL. Mini-open versus extended open release for severe carpal tunnel syndrome. Hand (N Y) 2015; 10(1):34-9.

20. Gülşen I, Ak H, Evcılı G, Balbaloglu O, Sösüncü $E$. A retrospective comparison of conventional versus transverse mini-incision technique for carpal tunnel release. ISRN Neurol 2013; 2013:721830.

21. Jugovac I, Burgić N, Mićović $V$, Radolović-Prenc L, Uravić M, Golubović V, et al. Carpal tunnel release by limited palmar incision vs traditional open technique: Randomized controlled trial. Croat Med J 2002; 43(1):33-6.

22. Zuo D, Zhou Z, Wang H, Liao Y, Zheng L, Hua Y, et al. Endoscopic versus open carpal tunnel release for idiopathic carpal tunnel syndrome: a meta-analysis of randomized controlled trials. J Orthop Surg Res 2015; 10:12.

23. Bromley GS. Minimal-incision open carpal tunnel decompression. J Hand Surg Am 1994; 19(1):119-20.

24. Cellocco P, Rossi C, Bizzarri F, Patrizio L, Costanzo G. Mini-open blind procedure versus limited open technique for carpal tunnel release: a 30-month follow-up study. J Hand Surg Am 2005; 30(3):493-99.

25. Cho YJ, Lee JH, Shin DJ, Park KH. Comparison of short wrist transverse open and limited open techniques for carpal tunnel release: a randomized controlled trial of two incisions. J Hand Surg Eur 2016; 41(2):143-7.

26. Shin EK, Bachoura A, Jacoby SM, Chen NC, Osterman AL. Treatment of carpal tunnel syndrome by members of the American Association for Hand Surgery. Hand (NY) 2012; 7(4):351-6. 